\title{
Representing Interventions from the Base of the Pyramid
}

\author{
Dr Santosh Jagtap (Corresponding author) \\ Post-doctoral researcher \\ Faculty of Industrial Design Engineering \\ Department Design Engineering, Delft University of Technology \\ Landbergstraat 15, 2628 CE, Delft, The Netherlands \\ Tel. (Office): 31-152-784-546 Fax: 0031-152781839 E-mail: S.N.Jagtap@tudelft.nl \\ Prof. Prabhu Kandachar \\ Faculty of Industrial Design Engineering \\ Department Design Engineering, Delft University of Technology \\ Landbergstraat 15, 2628 CE, Delft, The Netherlands \\ Tel. (Office): 31-152-785-769 Fax: 31-152-781-839 E-mail: P.V.Kandachar@tudelft.nl
}

\begin{abstract}
The base of the world economic pyramid, generally called the base of the pyramid (BoP), consists of four billion people with average per day income of four dollars. While some authors suggest a systems approach to design and develop products and services (i.e. interventions) for BoP markets, a little work has been carried out in this area. Furthermore, a framework to represent interventions in the BoP (i.e. socio-technical systems) and the resulting changes of state is not available. The reviewed studies on technical systems include models that represent inputs and the resulting changes of state in such systems; however, these studies have not been used to represent interventions in socio-technical systems. By modifying a causality model of technical systems, this study develops a framework called the IASTS model to represent interventions in a socio-technical system. It then explains the IASTS model by analyzing two case studies drawn from the BoP.
\end{abstract}

Keywords: Base of the pyramid (BoP), Socio-technical systems, Interventions, Changes of state, Representation

\section{Introduction}

The base of the world economic pyramid, generally called the base of the pyramid (BoP), consists of four billion people with average per day income of four dollars. Most of these four billion people live in rural villages, urban slums, or shantytowns. Usually these people have little or no formal education. They are hard to reach via the conventional means of communication and distribution channels. The quality and quantity of products and services available to them is usually inferior (Prahalad \& Hart, 2002). The authors state, "Low-income markets present a prodigious opportunity for the world's wealthiest companies - to seek their fortunes and bring prosperity to the aspiring poor".

Businesses can make profits in BoP markets and help the poor in satisfying their unmet or under-served needs (Prahalad \& Hart, 2002; Prahalad, 2004). Over the past several years, the design and development of products and services (i.e. interventions) for the BoP has been investigated by several authors from different disciplines (Prahalad, 2004; Whitney \& Kelkar, 2004; Kandachar \& Halme, 2008; UNDP, 2008; Jagtap \& Kandachar, 2009a; Eaton et al., 2009; London et al., 2009; Viswanathan et al., 2009; Rivera-Santos \& Rufín, 2009). Designing and developing products and services for BoP markets requires addressing diverse issues in these markets. Jagtap and Kandachar (2009b) synthesized the literature on these issues in the BoP. Their study found that the issues identified in the study conducted by the United Nations Development Programme (UNDP, 2008) are comprehensive and include those identified in other relevant studies. These issues are about: how businesses can gain information on BoP markets; under-developed regulatory frameworks; poor physical infrastructure; lack of knowledge and skills of BoP customers; and BoP customers' poor access to financial services.

In order to address diverse issues in BoP markets through the design and development of interventions, an integrated approach using knowledge from technical, social and management sciences has been proposed by Kandachar and Halme (2008). This approach is in line with the systems approach. While some authors have highlighted the need and importance of systems approach in the BoP, much less work has been carried out in this area. Systems approach has been investigated in areas other than the BoP. Some of the sectors in these areas are healthcare, economics, agriculture, energy, etc. These sectors and the BoP are socio-technical systems. A literature review on socio-technical systems showed that a generic framework to represent (i.e. to describe) interventions in a socio-technical system and the resulting changes of state has not been developed. Such a framework can help practitioners in designing and developing interventions to bring about intended changes of state in a given socio-technical system. In contrary, the literature on the theory of technical systems is rich, and includes studies that have developed frameworks to represent inputs in a technical system and the associated changes of state and actions. However, these studies have not been used to represent interventions in socio-technical systems and the resulting changes of state. The theory on technical systems can be used to 
represent interventions in socio-technical systems.

This study aims at developing a framework to represent interventions in a socio-technical system by using a causality model of technical systems. It then explains this framework by analyzing two case studies drawn from the BoP. In addition, we suggest an application of this framework to support practitioners in the design and development of interventions for the BoP.

\section{Background literature}

The concepts of systems thinking (or systems approach) were developed in different disciplines. Mingers and White (2010) list these concepts as - "parts/wholes/sub-systems, system/boundary/environment, structure/process, emergent properties, hierarchy of systems, positive and negative feedback, information and control, open systems, holism, and the observer".

The significance of systems thinking was documented from the start by its founders such as Churchman (1963) and Ackoff (1962). The literature on systems thinking is vast (e.g. general systems theory, complexity theory, cybernetics, system dynamic, soft systems methodology, etc.), and systems thinking can be applied in almost any domain. Below we present a brief review of relevant literature on systems thinking in the areas of socio-technical and technical systems.

\subsection{Socio-technical systems}

BoP markets are socio-technical systems. Systems approach is required in the design and development of interventions in the BoP. However, much less work has been carried out in this area excepting the studies of Subrahmanyan and Gomez-Arias (2008), Whitney and Kelkar (2004), Nielsen and Samia (2008), and Prahalad (2004). However, these studies have their specific aims, and focus on narrow areas of the BoP. For example, the work carried out by Subrahmanyan and Gomez-Arias (2008) aims at developing integrated frameworks to explain consumption patterns of the BoP-people. Nielsen and Samia (2008) apply general systems theory to analyze cases from the BoP in order to understand different stakeholders, and relationships between them. Prahalad (2005) examined nine social enterprise development cases, and identified four actors and interconnectivity between them. These studies, however, have not developed a framework to represent interventions and resulting changes of state in the BoP. Such a framework can be useful for practitioners in designing and developing interventions in the BoP.

Socio-technical systems have been investigated in areas other than the BoP. Systems approach to the social enterprise development is useful in understanding complex socio-technical systems, elements of the systems, and links between these elements. Churchman (1979) identified the following system characteristics in a development network.

- Social enterprise objectives (e.g. economic development).

- Actors (e.g. individuals, organizations, SMEs, NGOs, etc.).

- $\quad$ System inputs (e.g. human resources, training and education, etc.).

- Outputs of the system can be used to evaluate the system's performance. These outputs can be compared to the pre-set objectives.

- Transfer network represents the flow of inputs through the system. It also illustrates links between different elements of the system.

- Macro-environment (e.g. socioeconomic and political factors that affect and/or control activities and outcomes of the system).

- $\quad$ Time dimension represents the evolution of social enterprise development.

- Feedback mechanisms allow comparing outputs to objectives, and help the actors to improve system performance.

While the above characteristics are useful in the design and development of a social enterprise, Churchman has not synthesized these characteristics into a holistic framework. Checkland and Scholes (1990) developed soft systems methodology consisting of seven stages to tackle soft, ill-structured problems. However, they do not develop a model to represent solution, the ill-defined problem situation, and the resulting improvements in the problem situation.

Benathy (1994) developed a systems design approach to create new intended systems. His approach consists of five main steps which he calls 'spaces'. These 'spaces' are about exploration, organization of knowledge, generation of design solutions, experimentation or evaluation, and modeling and implementation. Geels and Kemp (2007) examine change processes in a socio-technical system due to different types of innovations such as 'reproduction', 'transformation', and 'transition'.

Harrison et al. (2007) develop a conceptual model called Interactive Sociotechnical Analysis (ISTA) in order to examine interactions between Healthcare Information Technologies (HIT) and healthcare organization's socio-technical system. They have identified five types of socio-technical interactions. One of the interactions, 
for example, is that new HIT changes existing social system. Again, these above studies have not developed a framework to represent interventions and associated changes of state in a socio-technical system. In addition, these studies do not use the studies that have examined technical systems and have developed models to represent inputs and the resulting changes of state in such systems.

There are several studies that apply systems approach to some specific areas. Some of these studies are in sectors such as healthcare, economics, agriculture, energy, etc. (Boston, 2000; Azapagic, 2003; Duczynski, 2004; Temel, 2005; Buchholz et al., 2007; Leveson et al., 2009). Azapagic, (2003) developed a framework to help businesses to achieve goals of social, economic, and environmental sustainability. The author applied systems approach to develop a framework, which is a step-by-step process, to integrate sustainability aspects into the organizational structure of a business. The steps in this framework are: sustainable development policy, planning, implementation, communication, and review and corrective action. Temel (2005) develop systems approach to help establish linkages between relevant organizations for information and knowledge flow in the case of a malaria control system. Buchholz et al. (2007) use systems approach to model the social, economic, and ecological interactions associated with bioenergy. These above studies also are not focused on developing a framework to explain interventions and resulting changes of state in a socio-technical system.

There are several studies that have examined technical systems and have developed models to represent inputs and the associated changes of state in such systems. However, these studies have not been used to represent inputs and the resulting changes of state in a socio-technical system. These studies on technical systems can be useful in representing socio-technical systems. We have used a model of causality found in the reviewed literature on technical systems to represent interventions in a socio-technical system. Note that our model is useful to represent interventions in a socio-technical system, and we do not claim this model as a model of causality for socio-technical system.

\subsection{Technical systems}

A given function of a technical system is achieved by a physical process, which is realized by physical effects and the geometric and material characteristics of the system (Pahl \& Beitz, 1996). Figure 1 shows two examples. The quantitative relationships between the physical quantities allow the description of physical effects. Several physical effects may need to be combined to achieve a function. On the other hand, a given function might be achieved by one of several different physical effects (e.g. a force can be amplified by the lever effect, the hydraulic effect, the wedge effect, etc.).

Hubka (1982) uses the terms process structure and function structure to explain and solve design problems. The process structure is a transformation between the input and output situations demanded by the problem. The function structure can be explained in terms of verbs allowing these processes to happen. Sembugamoorthy and Chandrasekaran (1986) explain function as the intended response of a device to external or internal stimuli. Behaviour is an explanation of how such a response is produced, and is described by a causal chain of states. A state establishes state of some objects in the world. Chakrabarti (1993) proposes function as "a relation (or relations) between at least two situations, describing the measurable responses of a device to measurable external stimuli". He proposes form as "one or several structural descriptions of a solution, and could be described by one or a set of situations". Bell (2004) defines the term structure as "the physical composition of the device; its components and connections"; behaviour as "how a device works, what it does in terms of its internal properties"; function as "a device's behaviour expressed in terms of its purpose"; and purpose as "the need that the device is intended to fulfil". He states that the above concepts provide abstract description of the previous concept; for instance, function is abstraction of behaviour.

Pahl and Beitz (1996) define side effect as "functionally undesired and unintended effect of a technical system on a human or on the environment". Chakrabarti and Johnson (1999) discuss the issue for identifying side-effects in conceptual solutions. They define side effects as "effects whose outputs affect the intended operations of a system". In order to activate physical effects, the right 'inputs' and right 'contextual parameters' are necessary. The authors have provided an example - "activation of a piezoelectric effect requires stressing (input) of certain crystals (context)".

There are multiple meanings and representations of function, form, design problems and solutions (Chakrabarti, 1993). Chandrasekaran and Josephson (1997) state, "there is also quite a bit of confusion between function and behavior in the literature".

The SAPPhIRE model of causality provides a rich causal explanation of a physical phenomenon and attempts "to reach a non-arbitrary degree of detail of behavioural explanation" (Chakrabarti et al., 2005). The SAPPhIRE (State-Action-Parts-physicalPhenomenon-Inputs-oRgan-physicalEffect) model explains the relationships between the following seven constructs:

- parts - "a set of physical components and interfaces constituting the system and its environment of interaction";

- state - "the attributes and values of attributes that define the properties of a given system at a given instant of time during its operation"; 
- organ - "the structural context necessary for a physical effect to be activated";

- physical effect - "the laws of nature governing change";

- input - "the energy, information or material requirements for a physical effect to be activated; interpretation of energy / material parameters of a change of state in the context of an organ";

- physical phenomenon - "a set of potential changes associated with a given physical effect for a given organ and inputs"; and

- action - "an abstract description or high level interpretation of a change of state, a changed state, or creation of an input".

Jagtap (2009) modified Chakrabarti et al.'s (2005) SAPPhIRE model by proposing an additional construct 'stimuli' and two additional relationships 'embody' and 'affect'. They defined the construct 'stimuli' as follows: "input context necessary for a physical effect to be activated in the presence of the relevant organs". Different aspects of an input (e.g. measure of input's attribute) and/or relationships between inputs create 'stimuli'. The developed model is called the 'Sym-SAPPhIRE' model of causality (see Figure 2). This model thus provides a rich causal explanation of an action.

The Sym-SAPPhIRE model can be useful in tackling the confusion created by the multiple meanings and representations of concepts such as function, behaviour, structure, etc. The constructs 'parts' and 'organs' explain the structure of a device, and the construct 'changes of states' describes the behavior of a device. Chakrabarti et al. (2005) state, "In our view, function is seen as specific, limited, intended aspects of the rich causal behaviour of artifacts embedded in and in conjunction with the environment in which it operates, and could be seen as: state change: attained, final state; inputs; I/O (input/output) transformation; creation of the context for physical effects to appear, i.e., organs, etc."

The Sym-SAPPhIRE constructs for a system transmitting power through a shaft are as follows (see Figure 3):

- parts: shaft forms a revolute pair with bearings;

- organs: one degree-of-freedom of motion between the shaft and bearings, bearings fixed to a rigid support;

- input: torque applied to the shaft;

- stimuli: magnitude of the applied torque;

- physical effect: Newtonian laws of motion;

- physical phenomenon: rotation of the shaft;

- state: shaft in static state, and shaft in rotating state;

- action: power is transmitted through the shaft.

Action is interpretation of a change of state, and depends on the interpreter. This above action (i.e. power is transmitted thorough the shaft) is our interpretation.

\section{Research Methodology}

In a data-driven research approach (i.e. inductive approach), theoretical constructs are derived by analyzing the empirical data. In the case of a theory-driven approach (i.e. deductive approach), theoretical constructs are developed first, and these constructs are then tested using empirical data. In this research, we employ the theory-driven approach. There are two major steps in this research approach: (1) develop a framework to represent interventions and the resulting changes of state in a socio-technical system by adapting the Sym-SAPPhIRE model of technical systems; and (2) explain this framework by using case studies drawn from the BoP. In addition, we have provided an application of this framework to support practitioners.

\subsection{Selection of research method}

On the selection of research methods, Robson (2002) states, "The general principle is that the research strategy or strategies, and the methods or techniques employed, must be appropriate for the research questions you want to answer".

We used case studies to explain our framework because complete description on projects implemented by companies in the BoP was available in the examined case studies. This description was available in documents and this helped us to gain the advantages of document analysis. Document analysis is one of the unobtrusive data collection methods. Documents are not created specifically for the purpose of the research; hence, the reactive effect is mitigated (Robson, 2002; Bryman, 2004). However, there are some disadvantages of document analysis. For instance, the creators of documents can forget to document some information. Documents are written for many purposes and may not include researcher's purpose (Robson, 2002). However, document analysis fulfilled our aim of explaining the developed framework regarding interventions in a socio-technical system.

United Nations Development Programme (UNDP) led an initiative called 'Growing Inclusive Markets' (GIM) (UNDP, 2008). In this initiative, they analyzed 50 BoP-cases from ten different sectors such as energy, healthcare, etc. and from different countries. The documents providing complete description of these cases are available on 
the GIM's website (Note 1).

In order to explain the developed framework, we randomly selected two cases from the UNDP-study. One case is about a project where a company called Amanco designed and developed an irrigation system for low-income farmers from Latin America. The second case is about a project where a for-profit company, Afrique Initiatives, used Information and Communication Technologies (ICTs) to monitor health conditions of children from low-income families in Mali. We systematically analysed these cases to illustrate our framework. The data analysis method and its validation are presented further in Section 5.

\section{Development of a framework to represent interventions in a socio-technical system}

The Sym-SAPPhIRE model of causality provides a rich causal explanation of physical phenomena. Technical systems can be represented by using the Sym-SAPPhIRE model because in these systems we know the organs, stimuli, and the physical effects that can get activated in the presence of these stimuli and organs. Furthermore, in the design of technical systems, the information on physical effects is useful. For example, a database of physical effects along with the stimuli and organs required to activate these physical effects can assist practitioners in selecting appropriate stimuli and organs to achieve desired functions. In a technical system, in addition to desired physical effects, some unanticipated physical affects can also get activated. By careful analysis of these systems, these unanticipated physical effects can be identified, and thereby unanticipated changes of state and actions can be noticed. These unanticipated actions are generally called side effects.

Solutions developed by businesses in the BoP include social and technical systems. The technical systems can include physical products or infrastructure such electricity network, telecommunications infrastructure, roads, etc. These physical products can be represented using the Sym-SAPPhIRE model. However, we can not represent social systems using the Sym-SAPPhIRE model because we may not know physical effects in these systems and the Sym-SAPPhIRE model has been mainly developed for technical systems. In addition, we can not represent the relationships between the social and technical systems using this model.

To represent interventions and the resulting changes of state in a socio-technical system, we simplify the Sym-SAPPhIRE model as shown in Figure 4. We call this simplified model as the 'Interventions and Actions in a Socio-Technical System' (IASTS) model. Note that the IASTS model is not a model of causality for socio-technical systems. The system in this model consists of relevant elements in it such as people, technical systems (i.e. products), and operating procedures. This construct includes these different elements, relationships between them, and its environment of interaction. We thus define the construct system of the IASTS model as a set of interacting and interdependent elements (e.g. people, products, operating procedures) constituting a system and its environment of interaction. This is illustrated in the lower part of Figure 4. We have not explicitly included the constructs 'organs' and 'stimuli' of the Sym-SAPPhIRE model in the IASTS model. To simplify, we consider the construct 'organ' to be implicitly included in the construct 'system', and the construct 'stimuli' in the construct 'inputs'. We adopt Chakrabarti et al.'s (2005) definitions of the constructs, namely input, state, and action. The inputs include material, energy, and information requirements to create some changes of state for a system, and can consist of products and services. We use the terms 'inputs' and 'interventions' interchangeably. The changes of state, created by implementing an intervention in a system, are interpreted as actions. These actions are therefore subjective in nature. These changes of state and actions can create or affect inputs and system. In addition, the changes of state and action can be interpreted as inputs for further changes of state. The IASTS model also includes time dimension.

\section{Case studies: Data analysis and explaining the IASTS model}

\subsection{Data analysis method}

The main aim of the data analysis was to check if an intervention designed and developed for a BoP-system can be represented by using the IASTS model. Two case studies from the UNDP-study were selected. These cases were analyzed in order to verify if they could be represented by using the IASTS model. These cases were about projects implemented by companies in the BoP. The description of these cases was available in documents. In total we analyzed two documents on the two randomly selected cases. The data analysis method consisted of the following steps.

- Reading the document in order to understand the project in the BoP. This involved understanding aspects such as different issues addressed, nature of the developed intervention, changes in the BoP-system due to the implemented intervention, etc.

- Coding the document. The coding scheme consisted of labeling different paragraphs of the document with the relevant pre-defined constructs (i.e. system, inputs, changes of state, and actions) of the IASTS model. The definitions of these constructs are presented in Section 4. The context in which a paragraph of the document appeared played an important role in labeling that paragraph with the relevant constructs. The following items helped to establish the context: previous and subsequent paragraphs; and the section of the document. The labeling with different constructs is exemplified further in the present Section.

- Synthesizing the above labeled paragraphs into the IASTS model. 
The coding scheme is explained by drawing examples from the case study about a project where a company called Amanco designed and developed an irrigation system for low-income farmers from Latin America. The unfair prices and commercial intermediaries caused low productivity in the agricultural output of small farmers from the BoP in Latin America. Amanco developed an integrated irrigation system for these farmers who produced lemons on their land. This system aimed at increasing productivity of the agricultural output and at increasing the efficiency of water use. In order to implement the developed system, the company collaborated with partners from the BoP and with partners providing micro-credit. The company first developed the system in Guatemala and then in Mexico. We analyzed the data on the system developed in a community called La Testaruda (LT) in Mexico. Table 1 presents examples of the labeled paragraphs of the document regarding Amanco's integrated irrigation system in the LT community. The first example in this table presents information on the LT community, which is a part of the system where the final intervention, namely integrated irrigation system was implemented. Therefore, we labeled this description with the construct 'system' of the IASTS model. The second example describes an aspect (i.e. weak social capital) of the LT community and also describes an input to tackle the issue of weak social capital. Hence, we have labeled this description with the constructs 'system' (weak social capital of the LT community) and 'inputs' (promoting social gatherings) of the IASTS. The third example shows the changes of state due to the implementation of the intervention in the system. The changes of state have been interpreted as actions (e.g. renovated hope) in the fourth example.

In order to validate the data analysis method, 30 paragraphs from the document, regarding the Amanco's project, were coded to identify relevant constructs of the IASTS by two people - the researcher and one coder. Prior to this coding, the coder was explained the coding process with examples drawn from the case where the company Afrique Initiatives - implemented a healthcare intervention using ICTs in a small village in Mali. The coder was also explained the IASTS model with examples. The coder read the complete document before coding the given 30 paragraphs. There was $92 \%$ agreement between the researcher and the coder. This shows high inter-coder reliability. In addition, the coder was shown the representation of the case regarding Amanco's project by using the IASTS model, and was asked if the IASTS model represented the case accurately and comprehensively. He expressed that the IASTS model accurately and completely represented the case, and that the representation was easy to comprehend.

\subsection{Explaining the IASTS model}

Using the above data analysis method, we could represent the interventions, and the resulting changes of state and actions in the BoP using the IASTS model. In addition, we observed the following pattern in the two analyzed cases. In the two cases, the process of designing and developing an intervention affected or modified the existing system. As shown in Figure 5, this design and development process can be seen as 'inputs'. We call these 'inputs' as 'Design and Development Process Inputs' (DDPI). This DDPI changed the existing BoP system before implementing the developed intervention. This DDPI changed social capital, physical infrastructure, etc. in the BoP. DDPI was required as the final intervention could be employed only after some changes in the existing system. The modified system and final intervention in turn brought about some desired actions such as gaining profits and satisfying needs of BoP customers.

The following Section explains the case regarding Amanco's project in the LT community by using the IASTS model. Section 5.4 explains the second case regarding the healthcare intervention by Afrique Initiatives in Mali.

\subsection{Case study 1: Amanco's project in the LT community}

\subsubsection{Existing BoP system}

Amanco implemented the irrigation system in the LT community in Mexico. Initially, to gather information on this community, Amanco selected a social entrepreneur, Arturo García, the director of the NGO 'Sustainable Farmers Network' (RASA). Ashoka, an international civil society organization which promotes social entrepreneurship worldwide, helped Amnaco to select this social entrepreneur from RASA. RASA had experience of over 25 years in rural projects. The trust and legitimacy of RASA among the LT community was useful in gaining the required information on this community (i.e. existing BoP system). The farmers in this community were using outdated irrigation methods due to the lack of capital. The LT community was not aware of the importance of renewing the old lemon plants. The productivity of old lemon plants was poor. These farmers sold lemons in local markets or nearest cities without reaching larger wholesalers or supermarket chains.

The small farmers of the LT community felt neglected as the agriculture was not a priority for the government, and the distribution of public resources lacked a pro-poor approach. These small farmers were unable to afford the total cost of the new irrigation system and lacked the financial criteria and standards for getting the required capital for investing in this system. Furthermore, public subsidies were not reaching them.

\subsubsection{DDPI}

The design and development process started in 2005. 104 hectares of the LT community's land was selected. In order to tackle the lack of coordination and weak social capital in this community, social gatherings were arranged among farmers and their families for collaborative activities (e.g. preparing roads for excavation). 
Amanco carried out the hydraulic design and topographic mapping required for designing technical aspects of the new irrigation system. The company provided training to the technicians from the RASA for creating distribution channels, and for supporting and supervising the installation of this system. The installation of the new irrigation system was farmers' responsibility. The promotion of this system was RASA's responsibility, and was achieved through meetings, word-of-mouth strategy, and cooperatives of farmers. The financial model was developed by Amanco and RASA. This model involved 20\% down payment by farmers in three installments, $30 \%$ microcredit, and $50 \%$ public subsidy. RASA facilitated access to financing channels and public subsidies.

\subsubsection{Intervention and the modified BoP system}

The design and development process modified the existing system and created the final intervention, which is the new irrigation system. The modified $\mathrm{BoP}$ system resulted into coordination and increased social capital among small farmers of the LT community. Ten out of 52 farmers renewed their lemon plants by 2006. RASA could support and supervise installation of the new irrigation system, and the financial model was available. The final intervention consisted of three types of irrigation systems, namely 'drip', 'portable', and 'micro-sprinkling'. The price of the irrigation system was in the range 2500 to 3000 USD per hectare.

\subsubsection{Changes of state and actions}

The modified BoP system and intervention created some changes of state as follows:

- increase in the agricultural (i.e. lemon) output;

- reduction in labor cost and time required for irrigation;

- $60 \%$ savings in the consumption of water;

- reduction in the land erosion.

One of the farmers of the LT community interpreted the changes of state due to the new irrigation system as, "there is a renovated hope as we are starting to see the transformation".

\subsection{Case study 2: Representing the healthcare intervention in Mali using the IASTS model}

A for-profit company, Afrique Initiatives, established Pésinet with the aim of monitoring health conditions from low-income families. In order to fulfil this aim, Pésinet used Information and Communication Technologies (ICTs). The weight of a child is used as an indicator of its health. The pattern in the weight-change is analysed by a doctor to identify anomalies, if any, in the child's health. The child's mother subscribes to Pésinet's services by paying nominal fees. A representative from the Pésinet weighs her child(ren) twice a week. The information on this weight is transmitted to a local doctor using ICTs. After reviewing the weight chart, the doctor requests the visit of the mother and child if any anomalies are identified. Pésinet implemented the project in Mali in 2007. This project benefited hundreds of children. We explain our IASTS model by presenting information on the project in Mali (see Figure 6).

\subsubsection{Existing system}

Pésinet implemented the project in Coura, a region near the capital city Bamako in Mali. The challenges faced by the people in this region are: malaria, low income, poor or no literacy, poor sanitation, and lack of adequate water supply infrastructure. Affordability is a crucial issue as the average income of the families in this region is around approximately US\$4 a day.

In Mali, about $43 \%$ of children are underweight. The infant mortality rate is 218 per thousand. There is limited access to modern care. The limited number of trained doctors and nurses worsen the problems. Furthermore, $40 \%$ of the population lives more than 15 kilometers away from a health facility. However, in Mali, there are more mobiles phones than land lines, and this helps to contact remote areas.

\subsubsection{DDPI}

The main activities in the design and development process are as follows.

- Pésinet partnered with: two major French telecommunications companies, Alcatel-Lucent and Orange; two French schools, ESSEC Business School and Ecole Centrale Paris; a drug distributor, Medex; and a local NGO, Kafo Yeredeme Ton.

- Mali was selected to implement the project because Pésinet's partners, Alcatel-Lucent and Orange were already settled in the country.

- A team of students from the ESSEC Business School and the Ecole Centrale Paris carried out the design and development of the business plan (e.g. subscription fee-structure to cover the operating costs and child sponsoring for low-income families). In Mali, the subscription fees are 500 CFA per month (US\$1.05) and include access to medicines.

- $\quad$ Required technical systems, consisting of the use of mobile phones and specific applications for data transmission, were designed and developed by Alcatel-Lucent and Orange.

- The NGO, Kafo Yeredeme Ton from Mali, raised awareness by carrying out the marketing campaign together with Pésinet, by going door-to-door for a couple of months. The involvement of women community 
leaders in the programme helped to raise the awareness.

\subsubsection{Intervention and modified BoP system}

Mothers subscribe to Pésinet's service by paying a nominal fee. This service consists of weighing her children once a week at her home (twice a week for children under one) plus advice and treatment (if required) by a doctor. Children are weighed by local women called Pésinet representatives. The weight readings are transmitted to the doctor using SMS service of mobile phones. The doctor makes a decision regarding the visit of the mother and child based on the pattern in the change of the child's weight. One doctor can cover about 2000 children. When the doctor identifies an anomaly in the child's health, he/she sends an SMS to the Pésinet representative, who requests the mother and child to visit the doctor.

The design and development process modified the existing system and created the final intervention. The modified system resulted into increased awareness of mothers regarding the health issues of children. The mothers understood the importance of weight readings of children in identifying any anomalies in the child's health. The trust of local hospitals in Mali was achieved by informing them that the Pésinet's service would be a complementary service aimed at achieving early monitoring of children, and that the children with health issues would seek help from the regular healthcare system.

\subsubsection{Changes of state}

The intervention and the modified system helped to achieve the following changes of state. The Pésinet's service resulted in approximately 20 consultations per week for 400 children. This service helped mothers to get necessary advice and treatment for their children in a short time-scale attributed to the use of ICTs.

\subsubsection{Actions}

The changes of state can be interpreted as a step towards achieving the Millennium Development Goals (MDGs) set by the United Nations.

\section{Discussion and an application of the IASTS model}

The IASTS model was found to be useful in representing interventions and the resulting changes of state and actions in the analyzed cases from the BoP. In the case of the BoP, businesses deploy products and services to achieve some desired changes of state and thereby actions. These products and services act as an intervention or inputs in the BoP. The analyzed cases from the BoP show that the businesses modified the existing system before implementing the final intervention. The final intervention in the modified system created the intended change of state, which were interpreted as actions. Furthermore, the businesses partnered with NGOs from the BoP in the design and development process.

In order to achieve desired actions by implementing an intervention in an existing system, it is crucial to understand the existing system. This means that the understanding of an existing BoP system is important in the design and development of an intervention for the BoP. This understanding can include different characteristics of BoP stakeholders, existing state of the physical infrastructure, regulatory frameworks in the BoP, and relationships between them. In addition, this understanding can include information on the issues in the existing system such as under-developed regulatory frameworks, poor physical infrastructure, lack of knowledge and skills of BoP customers, etc. Partnering with stakeholders form the BoP (e.g. NGOs) and using their perspectives on the existing system can help to understand the existing system.

As the desired actions are interpretations of changes of state by different stakeholders, it is important to include these stakeholders in the design process. Different stakeholders can have different interpretations of changes of states - that is - they can interpret different actions based on their knowledge and experience. For example, BoP customers can interpret changes of state due to an intervention to identify whether or not that intervention would satisfy their needs or if they would accept the changes of state due to that intervention. It is therefore important to include the stakeholders from the BoP in the design of an intervention. This will also help to understand the existing BoP system as these stakeholders can provide their insights regarding that system.

The IASTS model is thus useful to explain the importance of gaining an in-depth understanding of an existing system and of partnering with stakeholders form this system in order to bring about desired actions by employing an intervention in the system.

An application of the IASTS model to support practitioners in designing and developing interventions for BoP markets is presented as follows.

As mentioned in Section 3, UNDP led the GIM initiative. In this initiative, they analyzed 50 BoP-cases from ten different sectors such as energy, healthcare, etc. and from different countries. Some part of this UNDP-study is reported by Gradl et al. (2008). While this UNDP-study has identified issues in BoP markets and strategies used by businesses to address these issues, it has not developed a framework to structure the information on the 50 cases. Structuring the information on such cases, regarding the interventions in BoP-markets, can help practitioners in designing and developing new interventions or in redesigning existing interventions in BoP-markets. 
The IASTS model is useful to structure the information on past and existing BoP-cases. This can be achieved by using the constructs of the IASTS for the BoP (e.g. existing BoP system, DDPI, modified BoP system, final intervention, actions, etc.). The case study on the Amanco's irrigation system in Mexico, has illustrated how the constructs of the IASTS can be used to structure the information on a BoP-case. Furthermore, the IASTS model allows a diagrammatic representation of information. The reviewed literature (Hoffman et al., 2002; Aurisicchio et al., 2007; Salustri et al., 2007; Kokotovich, 2008) suggests that the diagrammatic representation of information during the early phases of a design and development process has the following advantages:

- it helps to comprehend problems;

- it improves the effectiveness and efficiency of early design, and facilitates human cognitive processes

fostering innovation;

- information can be analysed at a faster rate than in a text format.

This implies that diagrammatic representation of information on past and existing BoP-cases can help practitioners in designing a new intervention or in redesigning an existing intervention. The IASTS model helps to diagrammatically represent information. Figure 7 exemplifies the diagrammatic representation of the information on the Amanco's intervention regarding the irrigation system. This diagrammatic representation can help practitioners who are involved in: (1) designing a new irrigation system in BoP markets; or (2) redesigning an existing irrigation system. It is thus clear that the IASTS model is useful to structure and represent information on BoP-cases, and a database of past and existing BoP-cases can be developed using the IASTS model. Such a database can help practitioners to: (1) easily comprehend these BoP-cases; and (2) generate solutions for the problems they are tackling.

Information on interventions or cases similar to the one being designed can help practitioners to understand different issues relevant to their design task. Analogical thinking/reasoning can assist in identifying similar interventions or cases. Ball et al. (2004) state, "Analogical reasoning entails the use of 'source' information from a previous problem-solving episode as a means to facilitate attempts at solving a current, 'target' problem". Holyoak and Thagard (1995) explain that, “....analogical thinking involves establishing a mapping, or systematic set of correspondences, between the elements of the source and the target analog".

The constructs of the IASTS model (e.g. actions, system, etc.) can be used to search for similar cases or interventions in the abovementioned database. A single construct (e.g. 'actions') or a combination of constructs (e.g. 'actions' plus 'inputs') can be used to search for similar cases or interventions. For example, in the design of a new irrigation system for a BoP market, practitioners might search a database of BoP-cases using the following criteria:

- 'action' to increase agricultural productivity (simple search);

- 'action' to increase agricultural productivity plus 'inputs' consisting of a drip irrigation system (combination search).

The search results can help the practitioners to generate appropriate solutions to tackle the problems they are solving.

\section{Conclusions}

A generic framework to represent interventions in a socio-technical system and the resulting changes of state can help practitioners in designing and developing interventions to bring about intended changes of state in a given socio-technical system. While the technical systems have been rigorously studied, these studies have not been used to represent interventions in socio-technical systems and the resulting changes of state. By modifying the Sym-SAPPhIRE model of technical systems, our study developed a framework (i.e. IASTS model) to represent interventions in a socio-technical system. We explained this framework by analyzing two case studies drawn from the BoP, and provided an application of this framework to support practitioners. The findings of the analysis of two case studies showed that the businesses modified the existing BoP system before implementing the final intervention. The final intervention in the modified BoP system created the intended changes of state, which were interpreted as actions.

Using the IASTS model, we systematically explained the importance of: (1) gaining an in-depth understanding of an existing system to bring about desired changes of state and actions through the design and development of interventions for that system; and (2) including different stakeholders from the existing system in the design and development process. The IASTS model represents interventions and the associated changes of state in a system

We exemplified an application of the IASTS model to support practitioners in designing and developing interventions for BoP markets. The IASTS model is useful in structuring information on the past and existing BoP-cases, and this information can be used in the design and development of a new intervention or in the redesign of an existing intervention. Further work involves developing tools and methods based on these proposed application of the IASTS model and evaluating them.

There are limitations to this study. We illustrated the IASTS model for the BoP using two case studies. A larger number of cases can help refine this model. This involves supplementing the currently used theory-driven 
approach with the data-driven approach.

\section{References}

Ackoff, R. L. (1962). Some Unsolved Problems in Problem Solving. OR, 13(1), 1-11.

Aurisicchio, M., Bracewell, R. H., \& Wallace, K. M. (2007). Characterising Design Questions That Involve Reasoning. Paper presented at the International Conference on Engineering Design, ICED'07, Paris, France.

Azapagic, A. (2003). Systems Approach to Corporate Sustainability: A General Management Framework. Process Safety and Environmental Protection, 81(5), 303-316.

Ball, L. J., Ormerod, T. C., \& Morley, N. J. (2004). Spontaneous Analogising in Engineering Design: A Comparative Analysis of Experts and Novices. Design Studies, 25(5), 495-508.

Banathy, B. H. (1994). Creating Our Future in an Age of Transformation. Performance Improvement Quarterly, 7(3), 87-102.

Bell, J. (2004). Representation of Function: University of Wales, Aberystwyth, UK.

Boston, J. (2000). The challenge of evaluating systemic change: the case of public management reform. International Public Management Journal, 3(1), 23-46.

Bryman, A. (2004). Social Research Methods (2 ed.): Oxford University Press.

Buchholz, T. S., Volk, T. A., \& Luzadis, V. A. (2007). A participatory systems approach to modeling social, economic, and ecological components of bioenergy. Energy Policy, 35(12), 6084-6094.

Chakrabarti, A. (1993). Towards A Theory for Functional Reasoning in Design. Paper presented at the International Conference on Engineering Design, ICED'93, The Hague.

Chakrabarti, A., \& Johnson, A. (1999). Detecting Side Effects in Solution Principles. Paper presented at the International Conference on Engineering Design, ICED'99, Munich.

Chakrabarti, A., Sarkar, P., Leelavathamma, B., \& Nataraju, B. S. (2005). A Functional Representation for Aiding Biomimetic and Artificial Inspiration of New Ideas. Artificial Intelligence in Engineering Design and Manufacturing, AI EDAM, 19(2), 113-132.

Chandrasekaran, B., \& Josephson, J. R. (1997). Representing Function as Effect. Paper presented at the Proceedings of Functional Modeling Workshop, Electricite de France, Paris, France.

Checkland, P., \& Scholes, J. (1990). Soft Systems Methodology in Action. UK: John Wiley.

Churchman, C. W. (1963). The X of X. MANAGEMENT SCIENCE, 9(3), 351-357.

Churchman, C. W. (1979). The Systems Approach: Revised and Updated. New York, NY: Dell.

Duczynski, G. (2004). Systems approaches to economic development for indigenous people: a case study of the Noongar Aboriginals of Australia. Futures, 36(8), 869-888.

Eaton, D., Wiersinga, R. C., \& Danse, M. (2009). Impact of high quality vegetable seeds for smallholder farmers in South East Asia. Paper presented at the International Conference on Impact of Base of the Pyramid Ventures.

Geels, F. W., \& Kemp, R. (2007). Dynamics in socio-technical systems: Typology of change processes and contrasting case studies. Technology in Society, 29(4), 441-455.

Gradl, C., Sobhani, S., Bootsman, A., \& Gasnier, A. (2008). Understanding the markets of the poor: A market system approach to inclusive business models. In P. Kandachar \& M. Halme (Eds.), Sustainability Challenges and Solutions at the Base of the Pyramid. Sheffield, UK: Greenleaf Publishing Limited.

Harrison, M. I., Koppel, R., \& Bar-Lev, S. (2007). Unintended Consequences of Information Technologies in Health Care-An Interactive Sociotechnical Analysis. J Am Med Inform Assoc., 14(5), 542-549.

Hoffman, R. R., Coffey, J. W., Haye, P. J., Cañas, A. J., Ford, K. M., \& Carnot, M. J. (2002). One Small Step for a Diagram, One Giant Leap for Meaning. Paper presented at the Diagrammatic Representation and Inference : Second International Conference, Diagrams 2002, Callaway Gardens, GA, USA.

Holyoak, K. J., \& Thagard, P. (1995). Mental Leaps: Analogy in Creative Thought. Cambridge, MA, USA: MIT Press.

Hubka, V. (1982). Principles of Engineering Design: Butterworth Scientific.

Jagtap, S., \& Kandachar, P. (2009a). Towards Linking Disruptive Innovations and BoP Markets. Paper presented at the International Conference on Engineering Design, ICED-09.

Jagtap, S., \& Kandachar, P. (2009b). Issues and Solutions in Designing Products and Services for the Base of the Pyramid. Paper presented at the International Base of the Pyramid Conference.

Jagtap, S. N. (2008). Capture and Structure of In-Service Information for Engineering Designers. Unpublished Thesis (PhD), University of Cambridge, U.K. 
Kandachar, P. (2010). Integrated Product Development - Discovering, defining, designing and delivering products \& services for the Emerging Markets. In T. London \& S. Hart (Eds.), Creating Mutual Value: Building Businesses and Alleviating Poverty with the Base of the Pyramid: Wharton, USA.

Kandachar, P., \& Halme, M. (2008). Farewell to pyramids: how can business and technology help to eradicate poverty? In P. Kandachar \& M. Halme (Eds.), Sustainability Challenges and Solutions at the Base of the Pyramid. Sheffield, UK: Greenleaf Publishing Limited.

Kokotovich, V. (2008). Problem Analysis and Thinking Tools: An Empirical Study of Non-Hierarchical Mind Mapping. Design Studies, 29(1), 49-69.

Leveson, N., Dulac, N., Marais, K., \& Carroll, J. (2009). Moving Beyond Normal Accidents and High Reliability Organizations: A Systems Approach to Safety in Complex Systems. Organization Studies, 30(2-3), 227-249.

London, T., Anupindi, R., \& Sheth, S. (2009). Creating mutual value: Lessons learned from ventures serving base of the pyramid producers. Journal of Business Research, In Press, Corrected Proof.

Mingers, J., \& White, L. A review of the recent contribution of systems thinking to operational research and management science. [doi: DOI: 10.1016/j.ejor.2009.12.019]. European Journal of Operational Research, In Press, Corrected Proof.

Nielsen, C., \& Samia, P. M. (2008). Understanding key factors in social enterprise development of the BOP: a systems approach applied to case studies in the Philippines. Journal of Consumer Marketing, 25(7), 446 - 454.

Pahl, G., \& Beitz, W. (1996). Engineering Design (K. M. Wallace, Trans. 2 ed.). London: Springer-Verlag.

Prahalad, C. K. (2004). The Fortune at the Bottom of the Pyramid: Eradicating Poverty through Profits. Upper Saddle River: Nj: Wharton School Publishing.

Prahalad, C. K., \& Hart, S. L. (2002). The Fortune at the Bottom of the Pyramid. strategy+business.

Programme, U. N. D. (2008). Creating Value for All: Strategies for Doing Business with the Poor, from http://www.growinginclusivemarkets.org/reports

Rivera-Santos, M., \& Rufin, C. (2009). Global village vs. small town: Understanding networks at the Base of the Pyramid. International Business Review, In Press, Corrected Proof.

Robson, C. (2002). Real World Research: A Resource for Social Scientists and Practitioner-researchers (2 ed.). Oxford, UK: Blackwell.

Salustri, F. A., Weerasinghe, J. S., Bracewell, R. H., \& Eng, N. L. (2007). Visualising early engineering design information with diagrams. Journal of Design Research, 6(1-2), 190-217.

Sembugamoorthy, \& Chandrasekaran, B. (1986). Functional Representation of Devices and Compilation of Diagnostic Problem-Solving Systems Experience, Memory and Reasoning. Hillsdale, NJ: Lawrence Erlbaum Associates.

Subrahmanyan, S., \& Gomez-Arias, J. T. (2008 ). Integrated approach to understanding consumer behavior at bottom of pyramid. Journal of Consumer Marketing, 25(7), 402 - 412.

Temel, T. (2005). A systems approach to malaria control: an institutional perspective. Health Policy, 71(2), 161-180.

UNDP (2008). Creating Value for All: Strategies for Doing Business with the Poor, from http://www.growinginclusivemarkets.org/reports

Viswanathan, M., Sridharan, S., \& Ritchie, R. (2009). Understanding consumption and entrepreneurship in subsistence marketplaces. Journal of Business Research, In Press, Corrected Proof.

Whitney, P., \& Kelkar, A. (2004). Designing for the Base of the Pyramid. Design Management Review, 15(4).

\section{Notes}

Note 1. Details of the UNDP's GIM study are available here: http://www.growinginclusivemarkets.org/ 
Table 1. Examples of the coding scheme

1 "This community was comprised by a total of 52 small lemon farmers, who on average System owned 2 hectares of land. Living conditions in this community were of high deprivation. Inhabitants had no access to sewage services and the majority of the houses had soil floors. In terms of farming activities, low-income lemon producers were subject to low levels of productivity due to the old age of their plants, the prevalence of archaic irrigation methods, the need for modern equipment and the lack of capital to invest in it."

2 "Weak social capital among small farmers in La Testaruda was another obstacle. The Irrigation Unit representatives mentioned as a key point the importance of promoting social gatherings among farmers and their families which ultimately help in the sharing of collaborative activities such as preparing the roads for excavations."

3 “Amanco's irrigation systems made possible a more efficient use of water. There were different percentages of water savings depending on the irrigation system used, with a maximum of $60 \%$."

4 “Amanco's project had helped to renew small farmers' hopes. La Testaruda producers expressed that they knew they were going to become an exemplar community for other towns, municipalities and states: there is a renovated hope as we are starting to see the transformation."

\begin{tabular}{|c|c|c|}
\hline Subfunction & $\begin{array}{c}\text { Physical effect } \\
\text { (independent of solution) }\end{array}$ & $\begin{array}{c}\text { Working principle } \\
\text { for a subfunction } \\
\text { (physical effect, geometric } \\
\text { and material characteristics) }\end{array}$ \\
\hline $\begin{array}{c}\text { Transfer } \\
\text { torque }\end{array}$ & Friction & Lever $_{\text {Amplify }}$ \\
muscular force
\end{tabular}

Figure 1. Achieving a sub-function using working principles that are developed from physical effects and geometric and material characteristics (Pahl and Beitz 1996) 


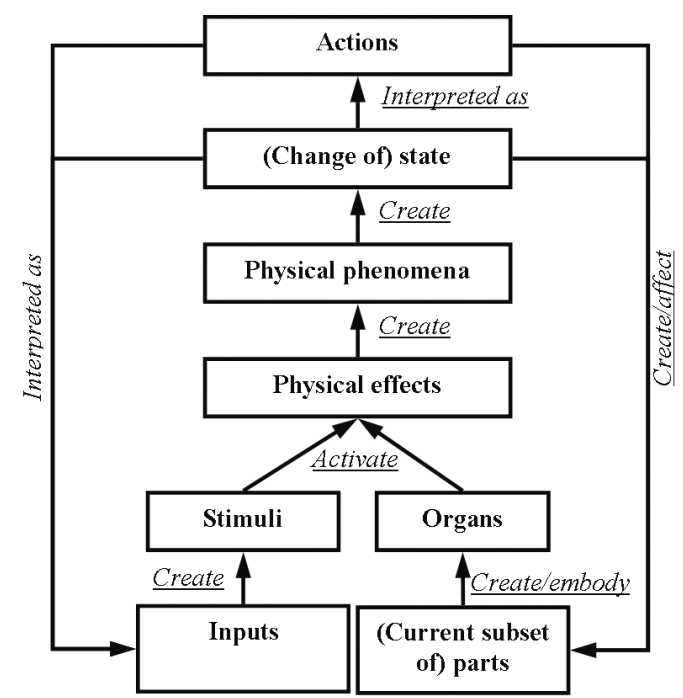

Figure 2. The 'Sym-SAPPhIRE' model of causality (Jagtap 2009)

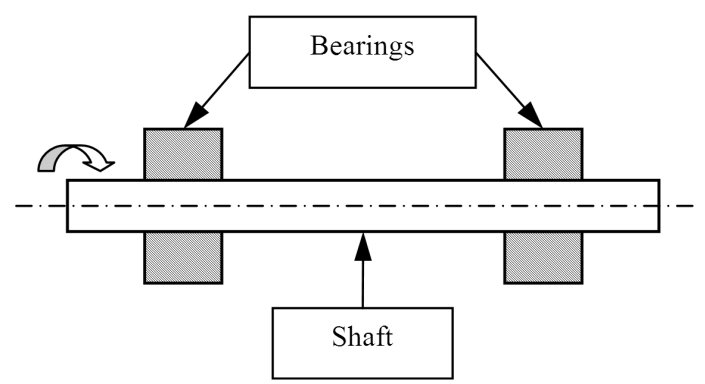

Figure 3. Transmission of power through a shaft

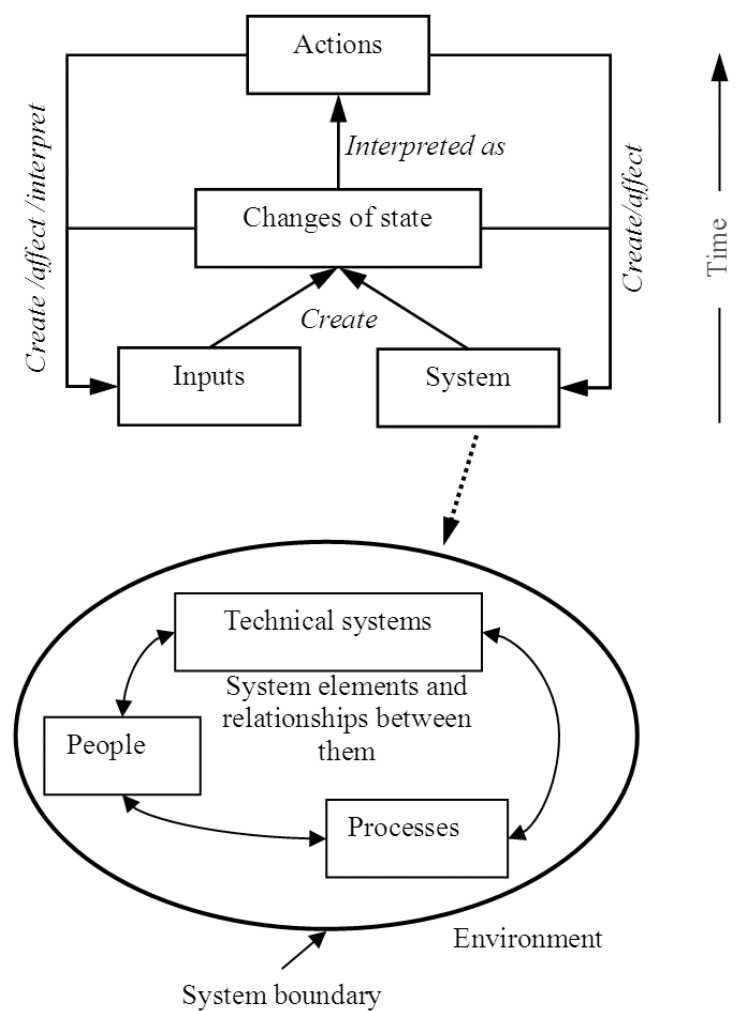

Figure 4. Interventions and Actions in a Socio-Technical System (IASTS) model 


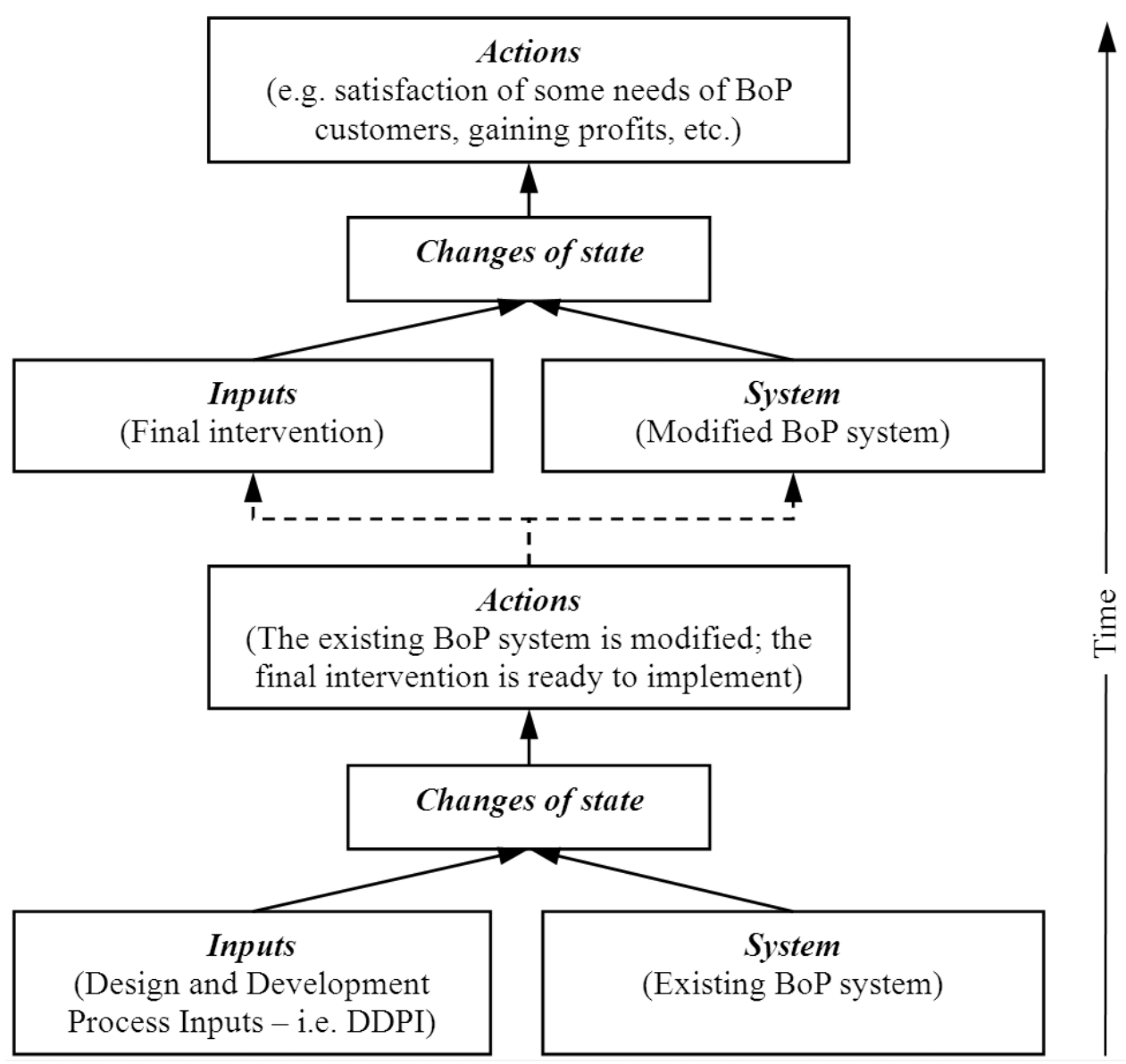

Figure 5. The IASTS for the BoP - modifying the existing BoP system before implementing the final intervention 


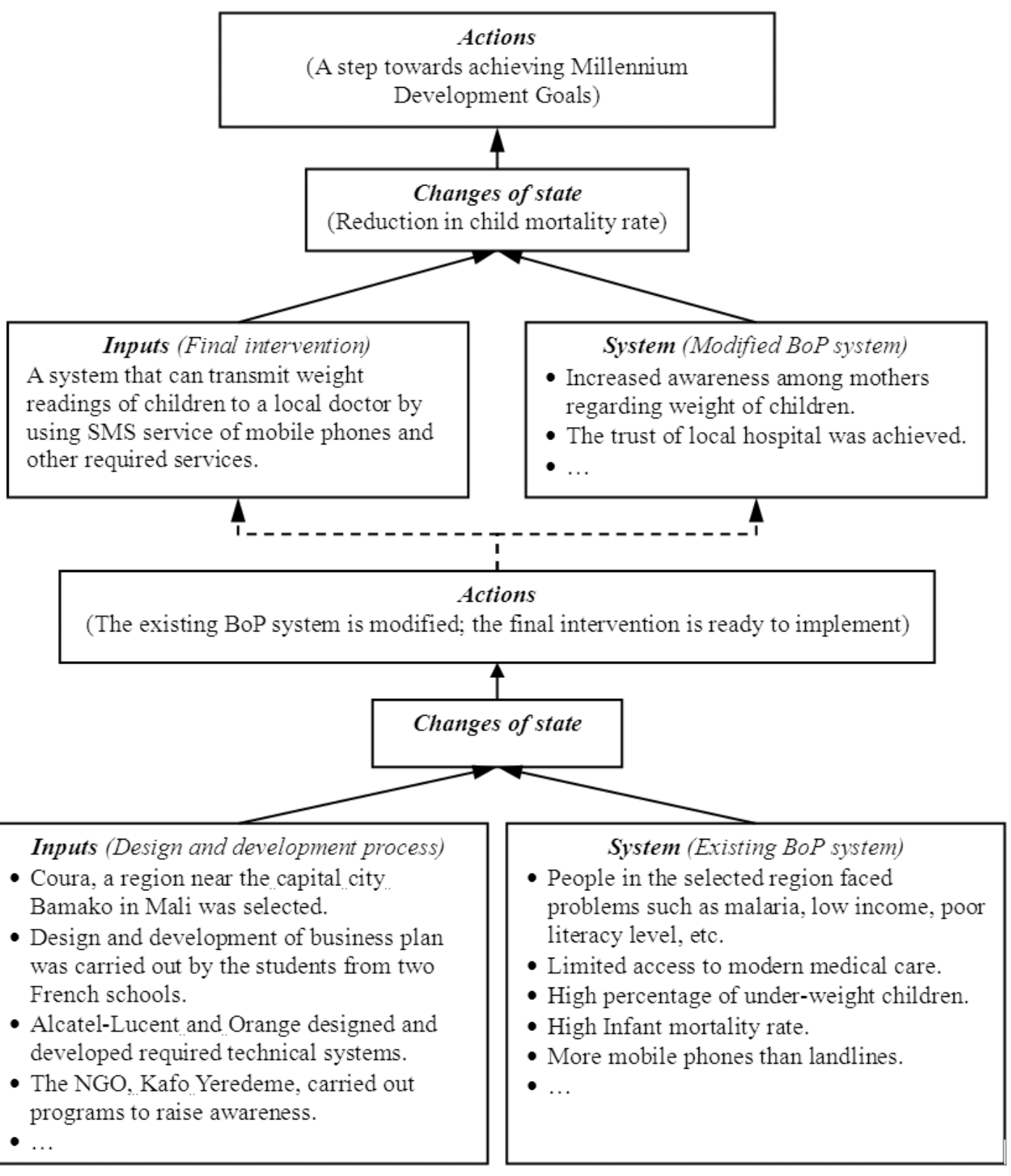

Figure 6. Actions due to the intervention in the modified BoP system (Case study 2) 


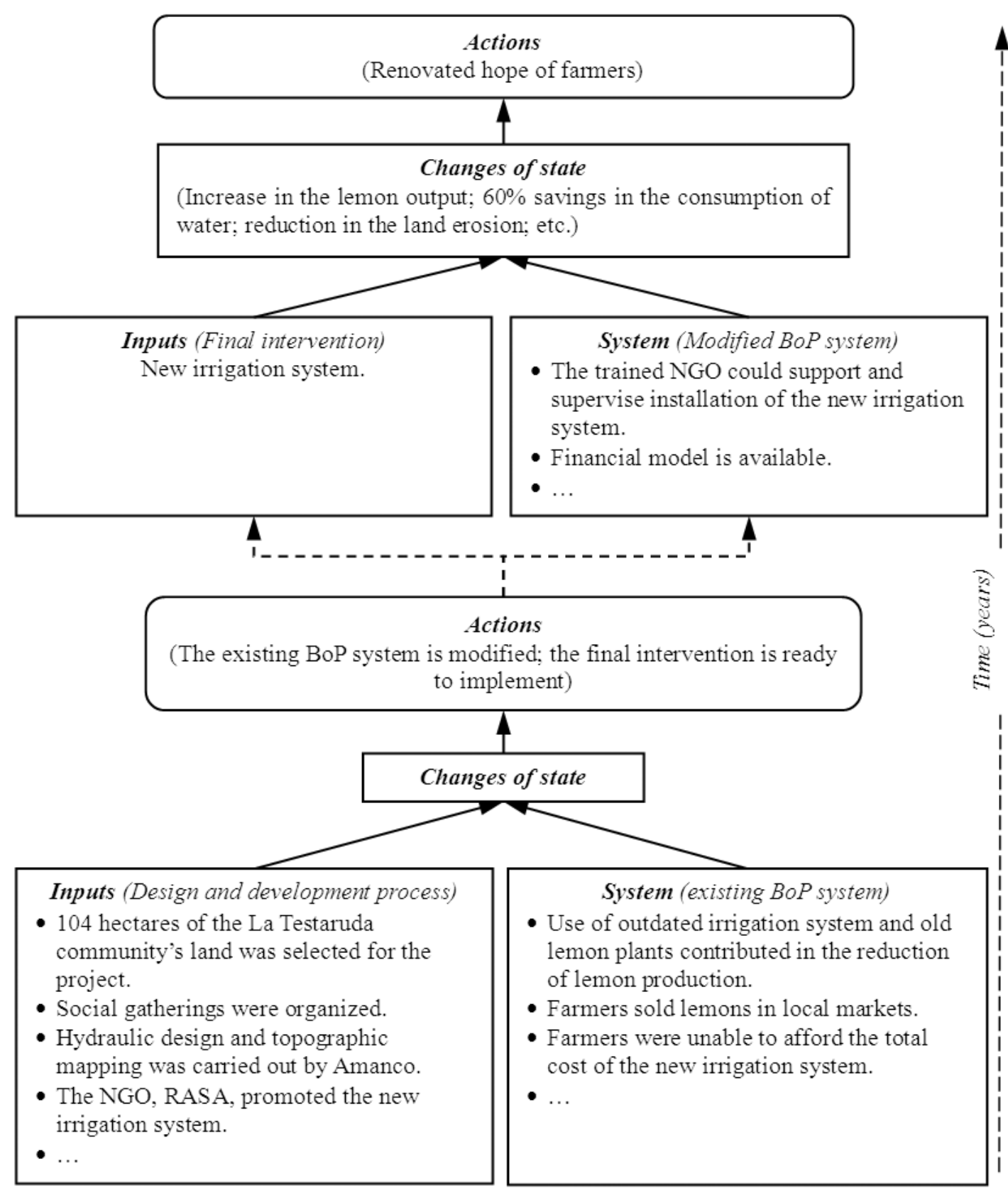

Figure 7. Diagrammatic representation of information using the IASTS model 